\title{
Low-speed impact damage analysis of aviation composite material structure
}

\author{
Jun $\mathrm{He}^{1, *}$, Meng $\mathrm{Cao}^{1}$, Zhishu Wang ${ }^{1}$, and Fanglin Cong ${ }^{2}$ \\ ${ }^{1}$ College of Aerospace Engineering, Shenyang Aerospace University, Shenyang, China \\ ${ }^{2}$ College of Civil Aviation, Shenyang Aerospace University, Shenyang, China
}

\begin{abstract}
Although the carbon fiber reinforced composite material has high specific strength and stiffness, design-versatility, anti-corrosion and other excellent features, but the impact resistance of composite structures is poor. Therefore, the composite laminates low-speed damage analysis has important significance. Based on a three-dimensional analysis theory of cumulative damage, using the commercial finite element analysis software ABAQUS to establish laminates subjected to low velocity impact finite element model. according to the numerical results and the consistency of the test results, shows that the used model of the article is reasonable and accurate, and the numerical simulation method is verified to be feasible. Finally, through the numerical simulation of process of laminated plates low speed impact damage, the damage characteristics and damage mechanism of the laminates at different times are analyzed, and the forming reasons and expanding rules of the main damage forms of fiber damage and matrix damage are revealed.
\end{abstract}

Keywords: Composite laminates; Low-speed damage; ABAQUS.

\section{Introduction}

Composite materials have excellent characteristics such as light weight, specific modulus, and good fatigue resistance [1-5]. As a new type of material, it has been widely used in the aerospace field, especially in the structure of aircraft, so that the aircraft has been effectively promoted and improved in many aspects. However, due to anisotropy, composite materials are susceptible to damage when subjected to an impact, and according to the degree of impact, the form of damage is also different, and its load-bearing capacity also changes[6,7].

This article focuses on the damage problem of laminated structure under low-velocity impact, and uses the three-step cumulative damage analysis method to study the impacted laminated structure: impact on the 5404/T300-1 laminated structure under low-velocity Test and use the ultrasonic C-scan flaw detector to scan the laminate to obtain the impact delamination damage area; use the finite element software ABAQUS to simulate, use the three-dimensional progressive cumulative damage method to analyze, and compare the test results and the numerical simulation results to prove the numerical simulation Analyze the feasibility of the method.

\footnotetext{
*Corresponding author: 20072999@sau.edu.cn
} 


\section{Low-speed impact test of composite material laminated structure}

\subsection{Preparation of test pieces}

The laminate material used in this test is a composite material of 5405/T300-1 with a geometric size of $250 \mathrm{~mm} \times 250 \mathrm{~mm}$ and material properties are shown in Table 1 . The layup method adopted for the test piece is a symmetrical layup method. There are 24 layers in total, and the thickness of the single layer board is $0.125 \mathrm{~mm}$, the total thickness is $3 \mathrm{~mm}$. It was formed by autoclave, and the elasticity and strength performance parameters of composite laminates were tested.

Table 1. Elastic properties of 5405/T300-1 laminate

\begin{tabular}{|c|c|c|c|c|c|}
\hline $\mathrm{E}_{1} / \mathrm{Mpa}$ & $\mathrm{E}_{2} / \mathrm{Mpa}$ & $\mathrm{v}_{12}$ & $\mathrm{G}_{12} / \mathrm{Mpa}$ & $\mathrm{G}_{13} / \mathrm{Mpa}$ & $\mathrm{G}_{23} / \mathrm{Mpa}$ \\
\hline 1787 & 7.56 & 0.283 & 135 & 135 & 98 \\
\hline
\end{tabular}

\subsection{Impact test}

Impact devices, jigs for imprisoning laminates, and hemispherical impact heads are the main test devices that constitute the low-speed impact damage test of laminates.

The quality of the punch used in this test is a hemispherical hammer with a diameter of, the height of the test punch is set to $\mathrm{h}=0.4002 \mathrm{~m}$, and the impact energy is $20.01 \mathrm{~J}$. After the test, an ultrasonic $\mathrm{C}$ scanner was used to detect damage to the damaged laminated structure. The damage when the impact energy is $20.01 \mathrm{~J}$ is shown in Figure 1 below. The damage image scanned by the ultrasound $\mathrm{C}$ scanner is shown in Figure 2. It can be observed from the figure that the shape of the damaged part is approximately a quadrilateral, and the damage area is calculated to be about $35.67 \mathrm{~cm}^{2}$ by scanning the image.

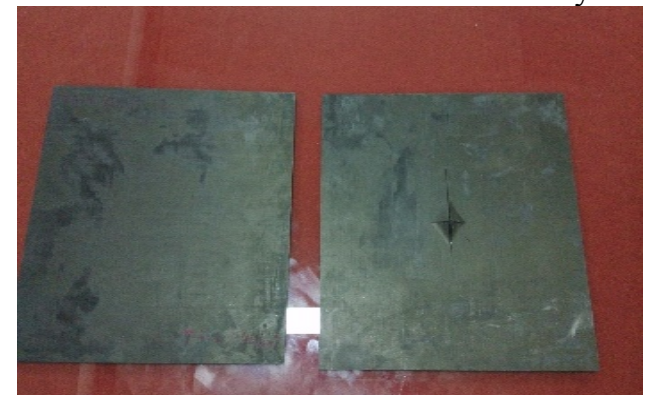

Fig. 1. Comparison of before and after injury

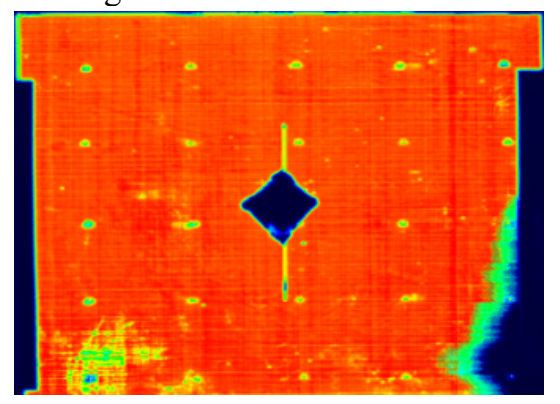

Fig. 2. C-scanned laminate damage image

\subsection{Experimental results}

Through the impact test of the laminate, under the action of the impact force, with the gradual penetration of the punch, the depth of the pit of the laminate becomes larger and the bulge on the back becomes more and more obvious, and the crack length of the substrate gradually increases. Extend along the boundary of the laminate. At the same time, the force-displacement curve is drawn from the data obtained through the low-speed impact experiment. The absorbed energy of the material under the impact energy of $20.01 \mathrm{~J}$ is calculated to be $2.38 \mathrm{~J}$ through the force-displacement curve. 


\section{Numerical study on low-velocity impact damage of composite laminates}

\subsection{Establishment of finite element model}

The composite laminate is composed of multiple fiber-reinforced single layers and interlayer bonding layers. The simulated laminate in this paper is the above-mentioned experimental specimen, with a geometric size of $250 \mathrm{~mm} \times 250 \mathrm{~mm}$, a single layer thickness of $0.125 \mathrm{~mm}$, and a total of 24 layers. The composite laminate after modeling has a total of 7195 solid elements, and the punch has 1193 solid elements. The numerical simulation diagram is shown in Figure 3.

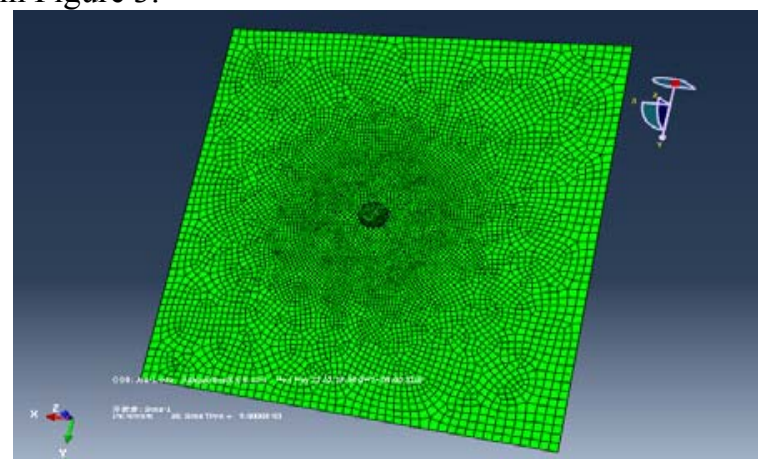

Fig. 3. Numerical simulation diagram of laminated structure

\subsection{Comparison of results between numerical simulation and experiment}

The comparative data of the impact test and numerical simulation of the composite laminate is shown in Table 2. It can be obtained that the damage area of the laminate under the same layup and the same impact energy is basically the same.

Table 2. Comparison of the experimental value and the simulated value of the delamination area

\begin{tabular}{|c|c|c|c|c|}
\hline $\begin{array}{c}\text { Impact } \\
\text { energy } / \mathbf{J}\end{array}$ & Laying angle & $\begin{array}{c}\text { Test value } / \\
\mathrm{cm}^{2}\end{array}$ & $\begin{array}{c}\text { Analog value } \\
/ \mathrm{cm}^{2}\end{array}$ & $\begin{array}{c}\text { Relative error } \\
(\%)\end{array}$ \\
\hline 20.01 & $\begin{array}{c}{[45 / 45 /-45 / 45 /-} \\
45 / 90 / 0 / 0 / 45 /-45 / 90 / 0]_{2}\end{array}$ & 35.67 & 34.85 & -2.29 \\
\hline
\end{tabular}

\subsection{Analysis of impact damage characteristics of laminates}

Figure 4 shows the progressive damage process of the matrix and fibers of the composite laminate at different times when the impact energy is 20.01J. The red that appears at the damage of the laminate is the matrix damage, and the colors other than the red are the fiber damage. 

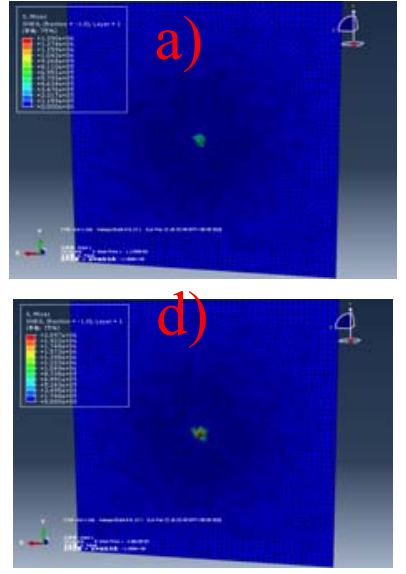
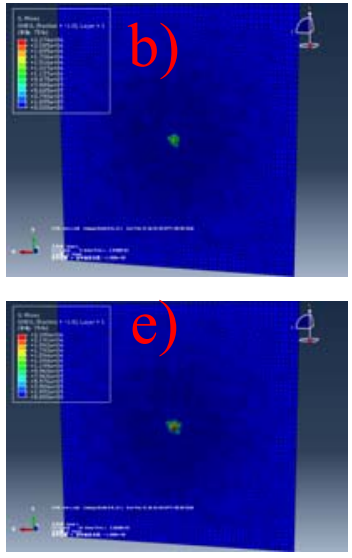
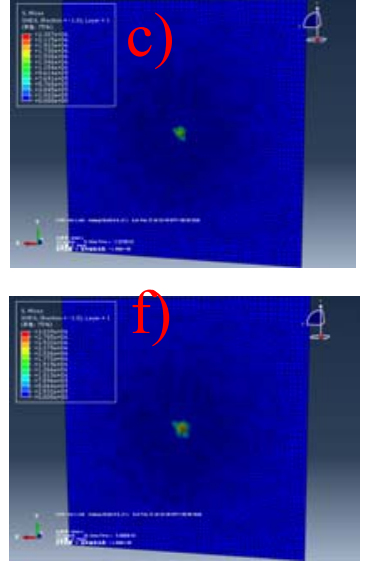

Fig. 4. Matrix and fiber damage diagrams at different times a) $t=1.18 \mathrm{~ms}, b) t=2.94 \mathrm{~ms}$, c) $\mathrm{t}=3.53 \mathrm{~ms}, \mathrm{~d}$ ) $\mathrm{t}=4.68 \mathrm{~ms}, \mathrm{e}) \mathrm{t}=5.81 \mathrm{~ms}, \mathrm{f}) \mathrm{t}=9 \mathrm{~ms}$

It can be observed from Figure 4 that at the beginning of the impact, the laminate is subjected to bending stress, the front side of the impact is subjected to compressive stress, and the reverse side of the impact is subjected to tensile stress. The reverse side of the laminate first produces tensile failure of the matrix. With the continuous decline of the punch, a significant depression appeared in the center of the impact, and the damage range of the matrix on the reverse side of the impact was further expanded and gradually expanded to the front of the impact.

\section{Conclusion}

Through the impact test of the laminate, under the impact of $20.01 \mathrm{~J}$, with the gradual penetration of the punch, the depth of the pit of the laminate becomes larger and larger, the protrusions on the back are more and more obvious, and the length of the substrate crack It also gradually grows and expands along the boundary of the laminate. When the impact load exceeds the load-bearing capacity of the laminate, the damage expansion rate is significantly slowed down. Through the comparison of simulation and test area, the relative error is $2.29 \%$. Therefore, the damage area obtained by ABAQUS simulation is basically consistent with the test results, which verifies the rationality and validity of the finite element model, and shows that the three-dimensional progressive cumulative damage analysis method is used Accuracy and reliability.

\section{References}

1. D.G.d. Santos, R.J.C. Carbas, E.A.S. Marques, L.F.M. da Silva, Reinforcement of CFRP joints with fibre metal laminates and additional adhesive layers, Composites Part B: Engineering 165 (2019) 386-396.

2. Y. Lin, Y. Huang, T. Huang, B. Liao, D. Zhang, C. Li, Characterization of progressive damage behaviour and failure mechanisms of carbon fibre reinforced aluminium laminates under three-point bending, Thin-Walled Structures 135 (2019) 494-506.

3. R. Khan, Fiber bridging in composite laminates: A literature review, Composite Structures 229 (2019). 
4. L. Pan, W. Ding, W. Ma, J. Hu, X. Pang, F. Wang, J. Tao, Galvanic corrosion protection and durability of polyaniline-reinforced epoxy adhesive for bond-riveted joints in AA5083/Cf/Epoxy laminates, Materials \& Design 160 (2018) 1106-1116.

5. D.-W. Lee, B.-J. Park, S.-Y. Park, C.-H. Choi, J.-I. Song, Fabrication of high-stiffness fiber-metal laminates and study of their behavior under low-velocity impact loadings, Composite Structures 189 (2018) 61-69.

6. Liu Yongqiang, Wang Xiangying, Tang Changhong, Feng Zhenzhou, Huang Chaoguang, Comparative study on bird strike resistance of four aircraft skin materials, Journal of Aeronautical Materials (05) (2015) 82-89.

7. Wenqiong $\mathrm{Tu}$, Jianqiao Chen, Junhong Wei, Research on anti-delamination performance of fiber/metal laminates under low-velocity impact, Chinese Journal of Solid Mechanics 33(002) (2012) 182-188. 